\title{
Size matching in lung transplantation: A narrative review
}

\author{
Tuba Apaydın ${ }^{1 *}$ and Ali Yeginsu ${ }^{2}$ \\ ${ }^{1}$ Thoracic and Cardiovascular Surgery Training and Research Hospital, SBU Istanbul Mehmet Akif \\ Ersoy, Istanbul, Turkey \\ 2Department of Thoracic Surgery, Kartal Kosuyolu Yuksek Ihtisas Training and Research Hospital, \\ Istanbul, Turkey
}

Received: 20 December, 2019

Accepted: 30 January, 2020

Published: 31 January, 2020

*Corresponding author: Tuba Apaydın, MD, Thoracic and Cardiovascular Surgery Training and Research Hospital, SBU Istanbul Mehmet Akif Ersoy, Istanbul, Turkey, Tel: 90 5052602798;

E-mail: tubaapaydn72@gmail.com

Keywords: Lung transplantation; Donor; Size match; Total lung capacity

ORCID: https://orcid.org/0000-0003-2169-1173

https://www. peertechz.com

Check for updates

\section{Abstract}

Background: Size matching between donor lungs and recipient chest space is an important technical problem that affects the outcome and survival following lung transplantation. The size of the lung can vary according to underlying disease, previous resections, and ethnicity, as well as height, age, and sex. Measurements of predicted total lung capacity according to height, age, and sex are frequently used, although other measurement methods are available.

Result: Excessively large or small donor lungs are undesirable for lung transplantation because they cause complications. In general, post-transplant outcomes are better when the donor lung is reasonably larger than the recipient thoracic cavity. However, larger donor lungs are not recommended for recipients with emphysema. We performed a literature search using Medline/PubMed, the Cochrane Library Database, and Scielo to identify articles published between June 2016 and July 2018 related to the effect of lung size matching on the prognosis of lung transplant patients. The literature primarily provides information regarding double lung transplantation with a predicted total lung capacity for the donor of $75 \%-125 \%$ of the predicted recipient total lung capacity. Data are lacking with respect to the size mismatch for single lung transplantation and recipients with restrictive pulmonary disorders.

Conclusion: This review presents detailed findings regarding size matching in lung transplantation.

\section{Abbreviations}

pTLC: predicted Total Lung Capacity; TV: Tidal Volume; COPD: Chronic Obstructive Pulmonary Disease; LDLLT: Living Donor Lobar Lung Transplantation; pFVC: predicted FVC; BOS: Bronchiolitis Obliterans Syndrome; PAH: Pulmonary Arterial Hypertension; VC: Vital Capacity; aTLC: actual Total Lung Capacity; BLT: Bilateral Lung Transplantation

\section{Introduction}

Donor-recipient lung size matching is a major factor that affects the outcome and survival following lung transplantation. The $28^{\text {th }}$ International Society of Heart and Lung Transplantation Registry reported that the height ratio of donor to recipient is a prognostic factor for death at 1year; the 1year-mortality rate is lower when the donor is taller than the recipient. A worse prognosis has been reported in the literature in cases involving a female donor and a male recipient. Predicted Total Lung Capacity (pTLC) can be evaluated with regression equations using sex, height, and age. A larger donor-recipient pTLC ratio is related to supranormal expiratory airflow, delayed appearance of bronchiolitis obliterans syndrome, and better survival rates [1]. However, excessively large or small donor lungs are undesirable. Excessively large donor lungs may lead to complications, such as atelectasis, hemodynamic instability, ventilatory failure, difficulty releasing secretions, and frequent infections [2].

The risks of primary graft dysfunction, additional airway complications (due to a bronchial diameter mismatch), persistent pleural effusion, infection, hyperinflation of the lung, elevated risk of operative bleeding, greater acute lung injury (due to higher tidal volume during mechanical ventilation), and the development of greater pulmonary vascular resistance are higher in cases involving extremely small donor lungs $[2,3]$. 
The 2003 consensus of the International Heart and Lung Transplantation Association suggested that the donor pTLC should be $75 \%-125 \%$ of recipient pTLC for a bilateral lung transplantation [4]. A criterion for single lung transplantation has not been established. However, it has been reported that considerably larger donors may be chosen for patients who are candidates for single lung transplantation due to Chronic Obstructive Pulmonary Disease (COPD). Patients are candidates for lung transplantation due to various causes, ranging from obstruction to hyperinflation issues (represented by COPD), or to restriction and contraction of the lung (represented by pulmonary fibrosis) [5]. In this review, we assessed the correlation between donor-recipient lung size matching in the current literature.

\section{Methods}

We conducted an English language literature search using Medline/PubMed, the Cochrane Library Database, and Scielo; we used the keywords "lung transplantation, size matching, mismatch, downsized graft, and oversized graft" for this search. We searched for articles published from June 2016 to July 2018; all data were synthesized and presented in detail.

\section{Lung size measurement methods}

Many measurement methods have been used to predetermine the recipient thorax cavity and donor lung size, including submammary chest perimeter [5], comparison of chest radiographs [6], anthropometry and weight comparisons [7], vital capacity [8], total lung capacity (TLC) and height comparisons [9], computed tomography, and volumetric studies [10]. However, none of these measurement methods guarantee ideal results.

Height, age, sex, ethnicity, recipient disease, and previous resections contribute to alterations in the measurements. Thoracic volumes differ between children and adults [10]. In men and women of similar height, lung volume is greater in men [10]. Lung volumes vary according to ethnicity [10]. Recipient disease affects thoracic volume: the thorax is larger in patients with emphysema and smaller in patients with fibrotic disease. Chest volume may be reduced due to cardiomegaly in patients with pulmonary arterial hypertension. Thoracic volume shrinks after pulmonary resection $[11,12]$.

pTLC is currently the most frequently used measurement method. TLC represents the total air volume in the lungs at the maximum inspiratory level. It is typically approximately 4-6L, as measured by plethysmography, and can be calculated with a formula obtained using height, age, and sex. However, it is not a flawless method, as age, ethnicity, and recipient disease status may vary; moreover, TLC measurements are physiological, while size matching is anatomically comparable [13]. The approach used by the European Respiratory Society calculates pTLC [14], according to the following formulas:

pTLC $(\mathrm{mL})$ in men: [(7.99 $\times$ height in meters $)-7.08] \times 1000$

pTLC (mL) in women: [(6.60×height in meters $)-5.79] \times 1000$
These formulas can be applied for heights of $1.55 \mathrm{~m}-1.95 \mathrm{~m}$ for men aged 18-70 years, as well as for heights of $1.45 \mathrm{~m}$ -1.80 m for women aged $18-70$ years.

Estimates of the actual TLC are occasionally difficult to determine due to the nature of recipient disease. In patients with pulmonary fibrosis, the chest wall and intercostal muscles are contracted, which causes rib crowding; however, the chest wall cavity widens with flattening of the diaphragm and dilation of the intercostal areas in patients with COPD [5]. Some studies have used radiological volumetric calculations, which are anatomic measurements that may provide a more accurate thoracic volume measurement than the estimated TLC formula $[13,15,16]$. Methods such as optoelectronic plethysmography or computed tomography may provide a more accurate diagnosis [1]. However, these methods do not have common application areas due to their practical difficulties.

\section{Management of a size mismatch in lung transplantation}

It may not always be possible to achieve a size match between the recipient and the donor. In such instances, it is necessary to minimize the mismatch via surgical manipulation. A bronchial diameter mismatch is frequently encountered with respect to a smaller donor lung. In these situations, instead of a telescopic bronchial anastomosis, the donor bronchus should be cut proximally, as much as possible, to ensure it is suitable for the recipient bronchus. Date, et al., [17], developed the upper lobe sparing living-donor lobar lung transplantation procedure for downsized grafts. To use this procedure, the recipient lung cannot be infected, and the interlobar fissure should be well defined. The total graft forced vital capacity should be $<60 \%$ of the predicted forced vital capacity in the recipient. In addition, the native upper lobes should be compared to the lower lobes on computed tomography or perfusion scintigraphy. Surgical lung resection $[18,19]$, delayed thoracic closure $[20,21]$, or single lung/lobe transplantation [17], can be performed to match size when an excessively large donor lung is present. The most common procedure is a wedge resection. Segmentectomy, lobectomy, or bilobectomy can also be performed $[18,19]$. Lung resections can be completed on the back table, soon after transplantation or during ex vivo lung perfusion $[22,23]$. A lobectomy is preferred in instances of donor pTLC/recipient pTLC $>1.20$ [1]. The middle lobe is generally resected on the right side, and the lingula is resected on the left side. This technique also provides a beneficial reduction in the anterior posterior diameter of the graft. Studies are presented in Table 1.

Single lobes can be transplanted in instances where greater size reduction is necessary. Transplantation of a complete lung on one side with a single lobe on the contralateral side or bilateral single lobe transplantation can be implemented in the context of bilateral lung transplantations. All lobes are proper candidates for transplantation. The proper lobe can be chosen according to its anatomical size compatibility with the recipient chest wall cavity. The left upper lobe is particularly chosen for patients with pulmonary hypertension and elevated cardiac volume, due to reduced volume of the lower part of the left hemithorax [24]. 
Table 1: Sizing for bilateral lung transplantation.

\begin{tabular}{|c|c|c|c|c|c|}
\hline Author, date & Patient Group & $\begin{array}{c}\text { Study Type } \\
\text { (Level of evidence) }\end{array}$ & Outcomes & Key results & Study weakness \\
\hline \multirow[t]{2}{*}{$\begin{array}{c}\text { Eberlein et, al. Nov 2012, Johns } \\
\text { Hopkins USA (24) }\end{array}$} & $\begin{array}{c}211 \text { BLT patients grouped into } \\
\text { undersized or oversized based on } \\
\text { pTLC ratio. }\end{array}$ & $\begin{array}{l}\text { Retrospective Cohort } \\
\text { Study (Level Ilb) }\end{array}$ & $\begin{array}{c}\text { Survival according to pTLC } \\
\text { ratio }\end{array}$ & $\begin{array}{l}\text { pTLC ratio }>1.0 \text { is related to } \\
\text { better survival }(p=0.015)\end{array}$ & $\begin{array}{l}\text { Non-randomised, } \\
\text { retrospective study. }\end{array}$ \\
\hline & & & $\begin{array}{c}\text { Survival according to } \\
\text { pTLC-ratio quartile relative } \\
\text { to quartile } 4 .\end{array}$ & HR 95\% Cl p-value & $\begin{array}{l}\text { Heterogeneous recipient } \\
\text { population diagnosis }\end{array}$ \\
\hline \multirow[t]{2}{*}{$\begin{array}{l}\text { Ouwens JP et, al. December } \\
\text { 2002. University Hospital } \\
\text { Groningen, Netherlands (10) }\end{array}$} & $\begin{array}{c}80 \text { BLT; Emphysema } 36 \% \text {, other } \\
\text { COPD } 20 \% \text {, CF } 20 \% \text {, Pulmonary } \\
\text { Fibrosis } 8 \% \text {, Bronchiectasis } 9 \% \text {, } \\
\text { other } 7 \%\end{array}$ & $\begin{array}{l}\text { Retrospective Cohort } \\
\text { Study (Level Ilb) }\end{array}$ & $\begin{array}{l}\text { Median pTLC donor/ } \\
\text { recipient ratio }\end{array}$ & $1.01(0.72-1.42)$ & Retrospective study. \\
\hline & & & $\begin{array}{l}\text { Clinical or functional } \\
\text { complications }\end{array}$ & Not reported & $\begin{array}{c}\text { Heterogeneous recipient } \\
\text { population diagnosis }\end{array}$ \\
\hline \multirow[t]{2}{*}{$\begin{array}{l}\text { Miyoshi S et, al. April } 1999 . \\
\text { Osaka University Medical } \\
\text { School, Japan (9) }\end{array}$} & $\begin{array}{l}20 \text { BLT recipients with } \\
\text { emphysema or non-emphysema }\end{array}$ & $\begin{array}{l}\text { Retrospective Cohort } \\
\text { Study (Level Ilb) }\end{array}$ & $\begin{array}{l}\text { Correlation of predicted } \\
\text { donor to predicted } \\
\text { recipient VC }\end{array}$ & $\begin{array}{l}\text { Significantly associated } \\
\qquad(r=0.79, p=0.001)\end{array}$ & $\begin{array}{c}\text { Retrospective, no clinical } \\
\text { outcome data }\end{array}$ \\
\hline & & & $\begin{array}{l}\text { Correlation of post BLT } \\
\text { VC with predicted VC of } \\
\text { recipient }\end{array}$ & $\begin{array}{l}\text { Significant correlation } \\
\qquad(r=0.74, p=0.002)\end{array}$ & \\
\hline
\end{tabular}

The most effective use of donor lungs is realized with the pulmonary bipartitioning method. Bilateral transplantation can be performed in patients with $50 \%$ of the TLC of the donor by splitting the lobes into upper and lower portions. Another technique to reduce size of the lung for transplantation involves the use of living related or unrelated lobar donation [24].

Implanted lungs may be larger after transplantation, due to early onset of edema and inflammation; thus, they may not fit into the thoracic cavity, and it may not be possible to close the thorax during this early period. In such instances, the patient is maintained on mechanical ventilation for a few days without closure of the bony thorax (i.e., by simple closure of the skin or closure with a synthetic patch). The thorax can be closed completely, a few days after transplantation, when the edema and inflammation have improved and the lungs have returned to normal size. This process is regarded as delayed chest closure, and its results are quite successful and functional. However, this process has been reported to cause a substantial increase in the frequency of wound infections [21].

Another method for use of donor lungs is unilateral lung transplantation. Puri, et al., reported that 12 of 31 single lung transplantations were unplanned and four were performed because of an extremely large donor lung. The risk of a mismatch of an oversized lung implant in a single lung transplant is lower in recipients with pulmonary fibrosis because mediastinal shifting allows the implanted lung to expand over time. Miyoshi, et al., [7], reported that a left-sided lung can reach its original volume, whereas the right-sided lung can only expand to the size of the recipient hemithorax. Date, et al., [15], stated that single-lobe transplantation, with or without contralateral pneumonectomy, was a strategy used for oversized grafts in their hospital.

\section{Donor and recipient parameters}

Lung-specific criteria have been established to determine the functional capacity of the donor and to exclude organs likely to result in undesirable outcomes (Table 2) [25]. A major criterion is arterial oxygenation. However, arterial oxygenation may be diminished in the planned donor due to obesity or partial atelectasis. The current guidelines are insufficient for calculation of the benefit hazard ratio for the lower limit of donor arterial blood gases. The upper age is reportedly 55years. Aigner, et al., reported 61 years as the upper age limit for donors in their study, whereas the upper age limit for our donors was 54years [25].

Another important factor is the chest $\mathrm{X}$-ray findings of the donor. Bilateral infiltrations, contusions, and atelectasis may

Table 2: Lung spesific criteria that presents donor recipient parameters.

$$
\text { Age }<55 \text { years }
$$

ABO blood group incompatility

Clear chest radiograph

Arterial oxygen pressure $>300 \mathrm{~mm}$ mercury on fractional inspired oxygen of 1.0 and positive end-expiratory pressure on $5 \mathrm{~cm} \mathrm{H}_{2} \mathrm{O}$

$<20$ pack year smoking history

Absence of chest trauma

Absence of aspiration and sepsis

Sputum gram stain sample without bacteria, fungus and important amount of white blood cells

be present on a chest X-ray; these are sometimes difficult to discriminate from pneumonia or aspiration. The contralateral lung can be used in instances of unilaterally disturbed lungs. The current literature does not contain precise information regarding the use of donor lungs associated with abnormal chest X-rays. Furthermore, the literature suggests that donor smoking history be $<20$ pack-years; we used donors with a shorter smoking history.

One of the standard criteria is a negative donor sputum Gram stain. However, this is not available in all donor hospitals. We have only evaluated this criterion in donors with suspected colonization after evaluation of a chest X-ray, or when massive secretions were present on bronchoscopy. Other important factors are graft ischemic time and size matching. 
Graft ischemic time should be $<6$ hours. Adverse reactions have been noted after prolonged graft ischemic time in older donors. A low potassium dextran perfusion solution was useful in our transplantations, with minimal prolongation of ischemic time beyond 6hours [25].

\section{Recommended size matching strategies in lung trans- plantation}

Our review of the literature indicates that clinicians should perform size matching for lung transplantation. These recommendations are retrospective in nature [5]. The strategies that have been proposed regarding specific recipient donor size matching are briefly summarized in Table 3.

Table 3: Strategies proposed for lung transplantation regarding spesific recipient donor size matching.

1-Acceptable donor lung pTLC interval should be decided at the multidisciplinary transplant listing meeting. All imaging and spirometric measurements are considered at this meeting.

2-In emphysema patients, the donor pTLC should be between $67 \%$ and $100 \%$ of the current TLC of the recipient (plethysmographic)

In this interval, lung recipients have better postoperative FEV1, bronchiolitis obliterans syndrome (BOS) free period and survival compared to larger lung recipients.

-The lung should not be bigger than the current TLC of the recipient because the chest wall mechanics disrupts.

No specific criteria has been established for a single lung transplant in emphysema recipients.

- The mean postoperative FEV1 values at postoperative 3 months were reported to be optimal when the donor/recipient ratio was 0.89 in submammarial perimeter measurements.

3-There is not much deviation between donor pTLC and recipient current TLC in Pulmonary Arterial Hypertension (PAH).

- It is reported that donor pTLC should have up to $120 \%$ of the recipient pTLC.

The use of larger donor lungs in PAH increases survival. Median survival was found to be 831 days longer compared to $0.93 \pm 0.1$ at donor/recipient pTLC ratios of $1.24 \pm 0.1$ [26]

4-It has been accepted that the use of current TLC of pulmonary fibrosis recipient in size matching compliance is a limited information.

-Applicable donor pTLC interval should be determined by radiological and physiological evaluations.It is recommended that donor pTLC should be below or above $15 \%-20 \%$ of the recipient pTLC when single lung transplantation is planned for pulmonary fibrosis.

There is no ideal size matching when planning bilateral lung transplantation in patients with pulmonary fibrosis, but safety is improved when the donor pTLC is $15 \%-20 \%$ above or below the recipient current TLC and pTLC.

We generally prefer the donor lung to be larger than the recipient thorax in our clinic (donor/recipient pTLC $\geq 1$ ). We prefer donor lungs to be slightly smaller or of similar size for patients with emphysema. If the donor lung is larger than the recipient thorax, we first expand the recipient thoracic cavity to achieve a size match. Any excess pericardial fat tissue is excised. Uni/bilateral diaphragmatic plication is performed on an elevated diaphragm. Delayed chest closure is performed when the lungs do not adequately fit into the thorax after implantation. Only the skin is closed and the patient is maintained on mechanical ventilation support for 48-96hours. The thorax is then reopened; if the lungs continue to be larger than appropriate for the thorax, a lung resection is performed.
An attempt is made to close the thorax again with minimal resection.

Cadaveric lobar lung transplantation is preferred in instances where patients have an asymmetric hemithorax (e.g., previous lobectomy, destroyed lung, or hyperinflation). An emergency lobar transplant can be performed using an excessively large donor lung (donor pTLC/recipient pTLC $\geq 1.2$ ). Eberlein, et al. used a cut-off donor-recipient TLC ratio of 1 . The International Society of Heart and Lung Transplantation lung transplant donor acceptability criteria indicate that size matching is sufficient for bilateral lung transplantation and heart-lung transplantation is sufficient within the donor-recipient pTLC ratio of $0.75-1.25$. Recipient postoperative total lung volume or vital capacity is directly proportional to recipient pTLC or predicted vital capacity in both lung transplantation and single lung transplantation. Thus, some clinicians accommodate matching between donors and recipients by using the closest values between donor pTLC and recipient pTLC. Nevertheless, this protocol does not consider the underlying chest condition of the patient. Mason, et al., reported that choosing a donor for a patient with emphysema who has TLC $<67 \%$ or $>103 \%$ increases mortality rate, indicating the importance of the recipient chest capacity.

TLC is a common method for size matching in lung transplantation [1]. However, actual TLC, which is a spirometric parameter that evaluates the alveolar space in many disorders changes with the contribution of atelectasis. In such instances actual TLC does not exhibit a real change in the pleural space. Louzzi, et al., reported that transplantation of lungs with a donor pTLC more than double the recipient actual TLC was feasible without any lung reduction procedures in patients with small pTLC (particularly patients with fibrosis). Although the donor pTLC should be $15-20 \%$ larger than that of a recipient with COPD, the limits of the ratio of donor to recipient pTLC change in situations involving pulmonary hypertension, fibrotic lung disease, and cystic fibrosis in the recipient [1] Lung fibrosis reduces intrathoracic volume; thus, matching lungs using pTLC involves a degree of risk. Nevertheless, the risk of mismatching is lower in a single lung transplantation for a recipient with pulmonary fibrosis, due to the potential for increased expansion of the pleural space [5]. The underlying diagnosis is also important for the post-transplant prognosis. Patients with interstitial pulmonary fibrosis present with bronchiolitis obliterans syndrome earlier than do patients with COPD; they also exhibit shorter survival [27].

\section{Conclusion}

Size matching in lung transplantation is an important issue that affects outcome and survival. Because of donor shortages, surgeons occasionally use size-mismatched donors. Although there is no ideal measurement method, pTLC is a practical and effective method currently used by many clinics and hospitals. However, the prognosis after lung transplantation depends on many factors and size matching should be planned with consideration of these variables. 


\section{Highlights}

- Donor-recipient lung size matching is a major factor affecting survival and outcomes in lung transplantation.

- Applicable donor pTLC interval should be determined by radiological and physiological evaluations.

- On the other hand, prognosis after lung transplantation depends on many factors and size matching should be planned considering these variables.

\section{References}

1. Eberlein M, Reed RM, Maidaa M, Bolukbas S, Arnaoutakis GJ, et al. (2013) Donor-Recipient Size Matching and Survival after Lung Transplantation. A Cohort Study. Ann Am Thorac Soc 10: 418-425. Link: http://bit.ly/319tMYt

2. Park $\mathrm{CH}$, Kim TH, Lee S, Paik HC, Haam SJ (2015) New predictive equation for lung volume using chest computed tomography for size matching in lung transplantation. Transplant Proc 47: 498-503. Link: http://bit.ly/2U9h4r7

3. Eberlein M, Reed RM (2016) Donor to recipient sizing in thoracic organ transplantation. World J Transplant 6: 155-164. Link: http://bit.ly/2S3CQKd

4. Orens JB, Boehler A, de Perrot M (2003) Pulmonary Council, Internationa Society for Heart and Lung Transplantation. A review of lung transplant donor acceptability criteria. J Heart Lung Transplant 22: 1183-200.

5. Barnard JB, Davies O, Curry P, Catarino P, Dunning J, et al. (2013) Size matching in lung transplantation: an evidence-based review. J Heart Lung Transplant 32: 849-860. Link: http://bit.ly/37JWRvR

6. Noirclerc M, Shennib H, Giudicelli R, Latter D, Metras D, et al. (1992) Size matching in lung transplantation. J Heart Lung Transplant 11: S203-S208. Link: http://bit.ly/2vAHB6

7. Park CH, Haam SJ, Lee S, Han KH, Kim TH (2016) Prediction of anatomical lung volume using planimetric measurements on chest radiographs. Acta Radiol 57: 1066-1071. Link: http://bit.ly/2vuJktR

8. Griffith BP, Hardesty RL, Trento A, Paradis IL, Duquesnoy RJ, et al. (1987) Heart-lung transplantation: lessons learned and future hopes. Ann Thorac Surg 43: 6-16. Link: http://bit.ly/2tdsHSH

9. Miyoshi S, Demertzis S, Eckstein F, Hohlfeld J, Schaefers HJ (1999) Chest size matching in single and double lung transplantation. Jpn J Thorac Cardiovasc Surg 47: 163-170. Link: http://bit.ly/3aY10Dg

10. Ouwens JP, van der Mark TW, van der Bij W, Geertsma A, de Boer WJ, et al. (2002) Size matching in lung transplantation using predicted total lung capacity. Eur Respir J 20: 1419-1422. Link: http://bit.ly/2OeAmay

11. Kojima K, Kato K, Oto T, Mitsuhashi T, Shinya T, et al. (2011) Preoperative graft volume assessment with 3D-CT volumetry in living-donor lobar lung transplantations. Acta Med Okayama 65: 265-268. Link: http://bit.ly/2S3MiNI

12. Harik-Khan RI, Fleg JL, Muller DC, Wise RA (2001) The effect of anthropometric and socioeconomic factors on the racial difference in lung function. Am J Respir Crit Care Med 164: 1647-1654. Link: http://bit.ly/2u5I80V

13. Jung WS, Haam S, Shin JM, Han K, Park CH, et al. (2016) The feasibility of CT lung volume as a surrogate marker of donor-recipient size matching in lung transplantation. Medicine (Baltimore) 95: e3957. Link: http://bit.ly/2OfV75Y
14. Stocks J, Quanjer PH (1995) Reference values for residual volume functionalresidual capacity and total lung capacity. ATS Workshop on Lung Volume Measurements. Official Statement of The European Respiratory Society. Eur Respir J 8: 492-506. Link: http://bit.ly/20fD8fO

15. Hwang SH, Lee JG, Kim TH, Paik HC, Park CH, et al. (2016) Comparison of Predicted Total Lung Capacity and Total Lung Capacity by Computed Tomography in Lung Transplantation Candidates. Yonsei Med J 57: 963-967. Link: http://bit.ly/2S523nx

16. Chen-Yoshikawa TF, Date H (2018) Three-dimensional image in lung transplantation.Gen Thorac Cardiovasc Surg 66: 19-26. Link: http://bit.ly/37JPfJX

17. Date H, Aoyama A, Hijiya K, Motoyama H, Handa T, et al. (2017) Outcomes of various transplant procedures (single, sparing, inverted) in living-donor lobar lung transplantation. J Thorac Cardiovasc Surg 153: 479-486. Link: http://bit.ly/2Udzeb6

18. Eberlein M, Reed RM, Chahla M, Bolukbas S, Blevins A, et al. (2017) Loba lung transplantation from deceased donors: A systematic review. World $J$ Transplant 7: 70-80. Link: http://bit.ly/3b2fKfQ

19. Slama A, Ghanim B, Klikovits T, Scheed A, Hoda MA, et al. (2014) Lobar lung transplantation--is it comparable with standard lung transplantation? Transp Int 27: 909-916. Link: http://bit.ly/2tWH8ew

20. Loizzi D, Aigner C, Jaksch P, Scheed A, Mora B, et al. (2010) A scale for decision making between whole lung transplantation or lobar transplantation. Eur J Cardiothorac Surg 37: 1122-1125. Link: http://bit.ly/20cZWg8

21. Aguilar PR, Bemiss BC, Witt C, Byers DE, Kreisel D, et al. (2017) Impact of Delayed Chest Closure on Surgical Site Infection after Lung Transplantation. Ann Thorac Surg 104: 1208-1214. Link: http://bit.ly/37LcoLQ

22. Puri V, Guthrie T, Scavuzzo M, Kreisel D, Krupnick AS, et al. (2011) Singlelung transplantation in the setting of aborted bilateral lung transplantation. $J$ Transplant 2011: 535649. Link: http://bit.ly/2tXGttg

23. Mendogni P, Palleschi A, Tosi D, Montoli RM, Damarco F, et al. (2017) Loba Lung Transplantation from Deceased Donor: Monocentric Experience. Transplant Proc 49: 682-685. Link: http://bit.ly/2GJ2s9K

24. Aigner C, Mazhar S, Jaksch P, Seebacher G, Taghavi S, et al. (2004) Loba transplantation, split lung transplantation and peripheral segmental resectionreliable procedures for downsizing donor lungs Eur J Cardiothorac Surg 25 179-183. Link: http://bit.ly/2RJCKZc

25. Aigner C, Winkler G, Jaksch P, Seebacher G, Lang G, et al. (2005) Extended donor criteria for lung transplantation-a clinical reality. Eur J Cardiothorac Surg. 27: 757-761. Link: http://bit.ly/2UbtBdv

26. Eberlein M, Diehl E, Bolukbas S, Merlo CA, Reed RM (2013) An oversized allograft is associated improved survival after lung transplantation for idiopathic pulmonary arterial hypertension. J Heart Lung Transplant 32: 1172 1178. Link: http://bit.ly/2RGgVJY

27. Eberlein M, Reed R, Permutt S, Chahla MF, Bolukbas S, et al. (2012) parameters of donor-recipient size mismatch and survival after bilateral lung transplantation. J Heart Lung Transplant 31: 1207-1213. Link: http://bit.ly/37JRmNR

Copyright: ( $) 2020$ Apaydın T, et al. This is an open-access article distributed under the terms of the Creative Commons Attribution License, which permits unrestricted use distribution, and reproduction in any medium, provided the original author and source are credited. 